\title{
Squamous odontogenic tumor: A case report
}

\author{
Mervet Moussa, Marwa Mokbel ElShafei
}

\begin{abstract}
Introduction: Squamous odontogenic tumor is a rare benign locally infiltrative odontogenic tumor of epithelial origin and only a few cases, less than 50 , have been reported in literature. The challenge is in diagnosing the tumor is due to its close resemblance to acanthomatous ameloblastoma and well differentiated squamous cell carcinoma. Case report: Herein we report, not previously reported, characteristic case of squamous odontogenic tumor in the anterior maxilla in a teenager female. Conclusion: The diagnosis is predicated on recognition of the histopathologic features of squamous odontogenic tumor to obviate possible misdiagnosis of malignancy or ameloblastoma. The symptoms are modest. Squamous odontogenic tumor has a characteristic pathologic picture, which differs from ameloblastoma.
\end{abstract}

Keywords: Squamous odontogenic tumor, Odontogenic neoplasms, Anterior maxilla tumor

Mervet Moussa ${ }^{1}$, Marwa Mokbel EIShafei ${ }^{2}$

Affiliations: ${ }^{1} \mathrm{PhD}$, Professor of Oral Pathology, Cairo University and Misr International University, Cairo, Egypt; ${ }^{2} \mathrm{PhD}$, Associate Professor of Oral Pathology, Misr International University, Cairo Egypt.

Corresponding Author: Dr. Marwa Mokbel EIShafei, Misr International University, km28 Ismailia Road, Cairo, EGYPT; Ph: +2 01001692078; Fax Number: +20 24772038; Email: marwamokbel@gmail.com

Received: 18 March 2013

Accepted: 17 June 2013

Published: 01 November 2013
Moussa M, Elshafei MM. Squamous odontogenic tumor: A case report. International Journal of Case Reports and Images 2013;4(11):607-610.

$* * * * * * * * *$

doi:10.5348/ijcri-2013-11-391-CR-5

\section{INTRODUCTION}

Squamous odontogenic tumor (SOT) is a rare benign true odontogenic neoplasm, with less than 50 cases reported in literature [1]. Three main types are identified: intraosseous, mural (mural SOT like-proliferation in a cyst) and extraosseous form, aggressive and multifocal variant have also been reported [2, 3]. Recently, it has been reported to be associated with calcifying epithelial odontogenic tumor [4].

According to Manjunath et al., collection of previous cases in literature, SOT affects a wide age range. The minimum age is eight-year-old and the oldest one is seventy-four [1]. A male predilection is noted and the most frequent sites were the bicuspid-molar region of the mandible and the incisor-cuspid area of the maxilla, with almost same distribution between maxilla and mandible $[1,3,5]$. Radiographically, SOT often exhibits a characteristic unilocular and triangular-shaped radiolucency of the alveolar bone, with the wide base of the radiolucency localized between the diverging apices of the adjacent roots [1].

Histopathologically, SOT consists of islands of well differentiated non-keratinized squamous epithelium in a mature fibrous stroma. The epithelial islands, occasionally, show foci of central cystic degeneration or calcification [1]. Squamous odontogenic tumor is a rare tumor that supposedly develops from the remnants of dental lamina, or of the cell rests of Malassez (ROM), or gingival epithelium [1]. Adebiyi et al. concluded that despite the infiltrative power of SOT, it should be treated conservatively, and this agreed with previous and later 
works which stated that the usual treatment has been simple enucleation and recurrence has been rare [1, 4-6]. On the contrary, Ruhin et al. described a case of an aggressive SOT [3]. They recommended a management as a Pseudo-malignant tumor, especially, if located in the maxilla or is invading adjacent cortical bones. However, this kind of treatment depends on its local aggressive recurrence.

A few reports about the malignant transformation of SOT have also been reported by Ide et al. who conveyed its transformation into intraosseous squamous cell carcinoma [7]. The purpose of this article is to report this rare neoplasm as the first case identified as SOT in our dental school in Cairo Egypt and to review literature.

\section{CASE REPORT}

A 15-year-old female patient reported to our dental school complaining of mobility of teeth in the right anterior region of the maxilla for last three months. Clinical examination revealed a mild degree of expansion of the facial surface, the overlying mucosa appeared normal, and on palpation the area was slightly compressible but painless. The maxillary right central incisor and canine were mobile.

Based on the clinical and radiographic findings, the initial diagnosis of periodontosis was made and subjected for histologic examination. Histopathologic examination revealed a solid locally infiltrative benign odontogenic epithelial neoplasm composed of variably shaped (ovoid, round, cord-like structure) and sized of cytologically bland-looking mature stratified squamous epithelial islands randomly scattered throughout a dense mature fibrous connective stroma (Figures 1 and 2). These tumor islands did not show any evidence of peripheral columnar cells, reverse nuclear polarity or central stellate reticulum-like cells. The squamous cells are very uniform and exhibit no nuclear hyperchromatism, pleomorphism or mitotic activity, foci of microcystic degeneration was occasionally seen in some islands (Figure 3). Scattered chronic inflammatory cells were present in the stroma; these histopathological findings led us to the diagnosis of SOT.

\section{DISCUSSION}

To date, about 44 cases of squamous odontogenic tumor have been reported [1]. Due to the paucity of documented cases of SOT; the relative frequency among odontogenic tumors could not be stated.

While our reported case occurred in a 15-yearold female when compared to the age range stated by Manjunath et al. [1]. The SOT occurs in a broad age range, up to the eighth decade, with a mean age range about 38 years. A slight male predominance is also stated in their
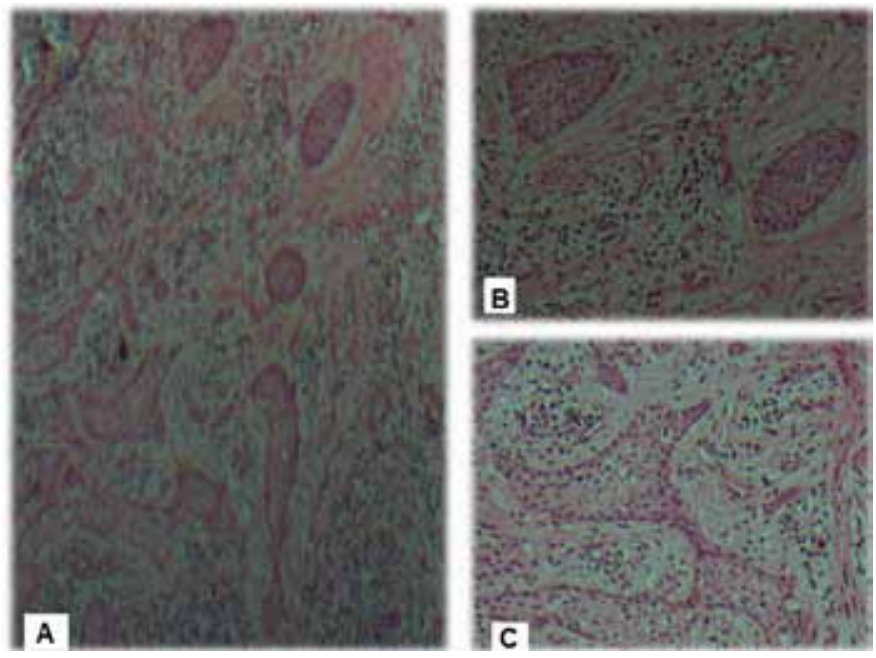

Figure 1: (A) The tumor consists of multiple scattered islands of squamous epithelium set in fibrocollagenous stroma heavily infiltrated with chronic inflammatory cells (H\&E x100), (B) The rounded nests of squamous cells (H\&E x400) and, (C) The thin epithelial cords anastomosing between the irregularly shaped tumor islands (H\&E stain, $\mathrm{x} 400$ ).

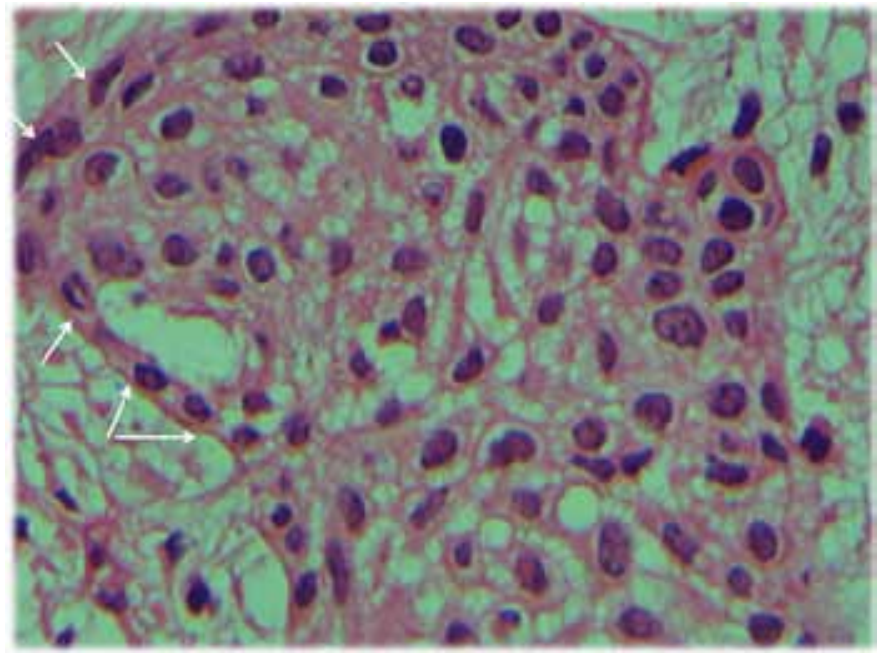

Figure 2: A higher magnification, of an irregular shaped island showing uniform squamous cells exhibiting no pleomorphism nuclear hyperchromatism or mitotic activity. Note the flattened peripheral layer of cells limiting the squamous island (arrows) (H\&E stain, x100).

work. Therefore, the gender is not of value in considering the diagnosis.

Considering the reported cases, the most common location for development of an SOT in the maxilla is anterior region and posterior in case of mandible with almost equal propensity to occur in both jaws. SOTs occurring in maxilla were found to be more aggressive than in mandible. This was mainly due to the anatomy, porous and medullary nature of bone. Our case was in the anterior region of the maxilla, extending posteriorly, 


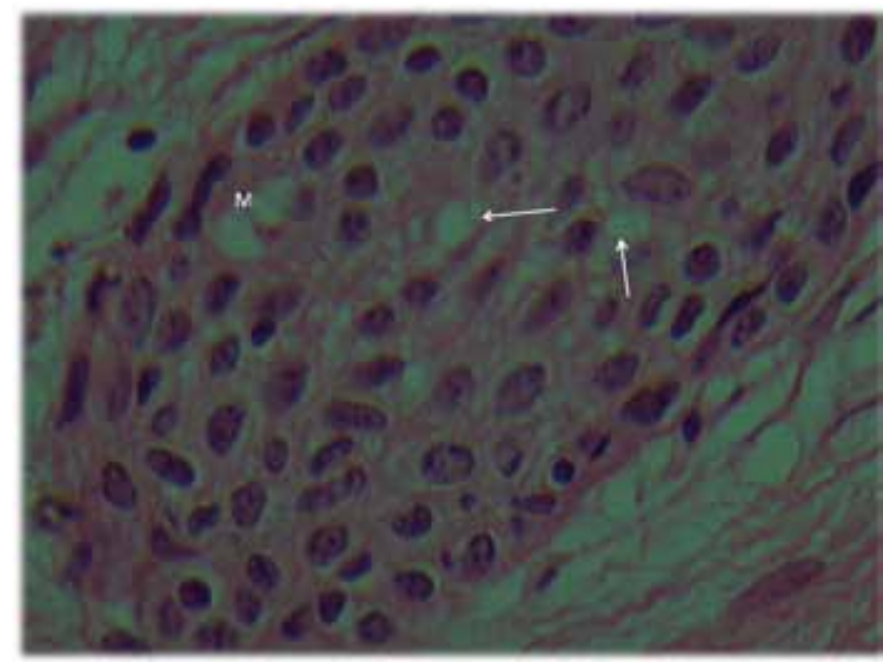

Figure 3: A high magnification photomicrograph of an island of benign squamous epithelium revealing the absence of peripheral columnar cells, palisading nuclei or central stellate reticulum. Note the evidence of microcysts (M) and focal vacuolization (arrows) (H\&E stain, x100o).

which matches with the common location of SOT. It also accords with most of the lesions, being in the periodontium of permanent teeth $[1,3,5]$.

A typical clinical image of SOT is a slowly growing central lesion that is nearly asymptomatic. Mild pain may coexist with slight swelling of the alveolar process and mobility of the neighboring teeth, an accidental discovery in a routine radiograph is not uncommon [8]. In our case, the patient only complained of mobility of teeth in the right anterior region of the maxilla. Upon examination a mild degree of expansion of the facial surface was revealed.

A well-defined unilocular radiolucency or multilocular pattern may be seen in the radiographic picture, relevant to the size of the lesion [6]. While, when a lesion is peripheral only pressure occurs on the alveolar bone leading to saucerization of the underlying bone [9]. As our case is an intrabony lesion, radiolucency is seen as an ill-defined area, proposing aggressiveness of the lesion, displacement of the canine and lateral incisors medially. The radiographic appearance of the lesion, occurring between the adjacent teeth in the tooth bearing area from the periodontal ligament space and the pattern of bone destruction seeming to emanate relatively uniformly from the areas of tooth roots lend credence to the theory of origin from the periodontal ligament area, i.e., the rests of Malassez [5].

Upon describing the histopathology of a typical SOT, benign squamous epithelial islands are seen, the squamous cells occupy the entire island with no columnar cells at the periphery neither palisading of the nuclei. These features enable the observers to eliminate the diagnosis of an ameloblastoma with squamous metaplasia as a differential one [1]. The epithelial islands might be surrounded with fibrous tissue condensation together with fibroblasts, which are considered a mesenchymal reaction to epithelial proliferation. The presence of keratin pearl, microcysts and calcification is not rare [9]. The precise histological picture, seen in our pathology lab, conforms to the classic picture mentioned above and this led us to the definite diagnosis.

Despite the ambiguous pathogenesis of SOT, still the origin from remnants of odontogenic epithelium is the most unswerving, including epithelial rests of Serres and Malassez. This theory is supported by the fact that most of the lesions are present in the periodontium of permanent teeth [1].

Kim et al. implied the mutation of the ameloblastin gene, which is found to be present in SOT, adenomatoid odontogenic tumor and ameloblastoma, to contribute in non-periodontal lesions [9]. It can also be a factor in the multicentric lesions. While Siar et al. suggested that ameloblastoma differs than SOT in the degree of differentiation of the lesions, depending on the results of their immunohistochemical stain of the two lesions with Notch 1,3 and 4 Jagged 1 and Delta 1 [10].

\section{CONCLUSION}

Squamous odontogenic tumor is a benign odontogenic true neoplasm. It is considered a distinct entity, its behavior differs from being well circumscribed and locally invasive, especially in maxilla. It should be treated first conservatively, but upon recurrence a more aggressive line of treatment is to be ensured. Very rare malignant transformation is reported. A proper diagnosis, depending on the histologic features should be ensured.

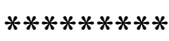

\section{Author Contributions}

Mervet Moussa - Substantial contributions to conception and design, Acquisition of data, Analysis and interpretation of data, Drafting the article, Revising it critically for important intellectual content, Final approval of the version to be published

Marwa Mokbel ElShafei - Acquisition of data, Analysis and interpretation of data, Drafting the article, Revising it critically for important intellectual content, Final approval of the version to be published

\section{Guarantor}

The corresponding author is the guarantor of submission.

\section{Conflict of Interest}

Authors declare no conflict of interest.

\section{Copyright}

(C) Mervet Moussa et al. 2013; This article is distributed under the terms of Creative Commons attribution 3.0 License which permits unrestricted use, distribution and 
reproduction in any means provided the original authors and original publisher are properly credited. (Please see www.ijcasereportsandimages.com/copyright-policy.php for more information.)

\section{REFERENCES}

1. Badni M, Nagaraja A, Kamath V. Squamous odontogenic tumor: A case report and review of literature. Journal of oral and maxillofacial pathology 2012 Jan;16(1):113-7.

2. Oliveira JA, Costa IM, Loyola AM. Squamous Odontogenic tumour like proliferations (SOT-LK) versus intra osseous squamous carcinoma in residual cyst. J Oral Maxillofac Surg 2006 Aug;64(8):1325.

3. Ruhin B, Raoul G, Kolb F, et al. Aggressive maxillary squamous odontogenic tumour in a child: Histological dilemma and adaptive surgical behavior. Int $\mathrm{J}$ Oral Maxillofac Surg 2007 Sep;36(9):864-6.

4. Tarsitano A, Agosti R, Marchetti C. The diagnostic and surgical management of a multifocal calcifiyng epithelial odontogenic tumor in the mandible and maxilla associated with a squamous odontogenic tumor: First reported case in the literature. Oral Surg Oral Med Oral Pathol oral radiology 2012 Apr;113(4):e6-11.
5. Adebiyi KE, Odukoya O, Taiwo EO. Squamous odontogenic tumour: Report of five cases from nigeria and review of literature. African journal of oral health 2006;(1-2):1-5.

6. Jones BE, Sarathy AP, Ramos MB, Foss RD. Squamous odontogenic tumor. Head Neck Pathol 2011 Mar;5(1):17-9.

7. Ide F, Shimoyama T, Horie N, Shimizu S. Intraosseous squamous cell carcinoma arising in association with a squamous odontogenic tumor of the mandible. Oral Oncol 1999 Jul;35(4):431-4.

8. Barrios TJ, Sudol JC, Cleveland DB. Squamous odontogenic tumor associated with an erupting maxillary canine: Case report. J Oral Maxillofac Surg 2004 Jun;62(6):742-4.

9. Kim K, Mintz SM, Stevens J. Squamous odontogenic tumour causing erosion of the lingual cortical plate in the mandible: A report of 2 cases. J Oral Maxillofac Surg 2007 Jun;65(6):1227-31.

10. Siar $\mathrm{CH}$, Nakano K, Ng KH, Tomida M, Nagatsuka $\mathrm{H}$, Kawakami T. Squamous odontogenic tumor of the mandible: A case report demonstrating immunoexpression of Notch1, 3, 4, Jagged1 and Delta1. Eur J Med Res 2010 Apr 8;15(4):180-4.
Access full text article on other devices

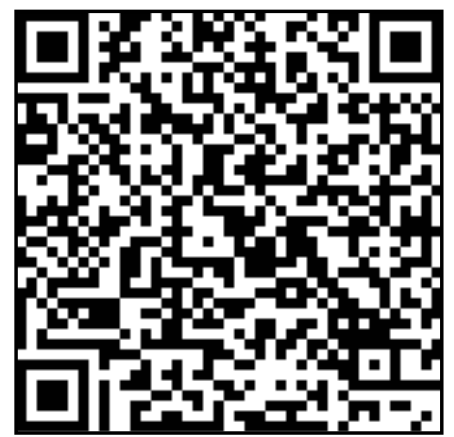

Access PDF of article on other devices

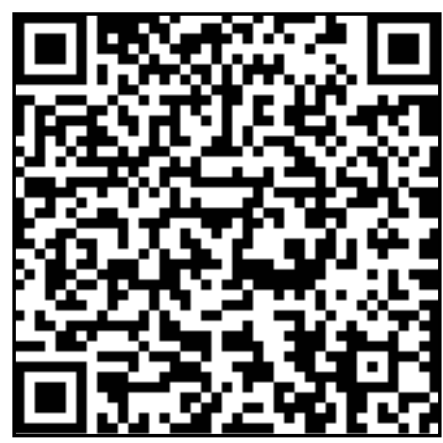

